\title{
Teleology, CaUSATion AND THE ATLAS Motif IN Plato's PHAEDo
}

\author{
DANIEL VÁZQUEZ \\ Autonomous University of Barcelona, Spain \\ svazqueh@gmail.com
}

\begin{abstract}
In this paper, I propose a new reading of Phaedo 99b6-d2. My main thesis is that in 99c6-9, Socrates does not refer to the teleological $\alpha i \tau i \alpha$ but to the $\alpha i \tau i \alpha$ that will be provided by a stronger 'Atlas' (99c4-5). This means that the passage offers no evidence that Socrates abandons teleology or modifies his views about it. He acknowledges, instead, that he could not find or learn any aiti $\alpha$ stronger than the teleological one. This, I suggest, allows an interpretation of the Phaedo in which Socrates offers a consistent account of the $\alpha i \tau i \alpha$ of generation and destruction.

KEYWORDS: deuteros plous, Platonic causes, forms, nous.

* This research was funded by a FAPESP fellowship number 2016/11848-9 and the European Union's Horizon 2020 research and innovation programme under grant agreement No 758145 .
\end{abstract}

In the traditional reading of Phaedo 99c6-9, Socrates recognises that he would be glad to learn the teleological $\alpha i \tau i \alpha$, but he has been unable to find it himself or learn it from someone else. Even if there is no consensus regarding how definitive or complete, this is taken to imply an abandonment of the teleology that was introduced before (97c4-6; 99c1-3, 99c5-6). In this paper, I propose a new reading of the text. My main thesis is that in 99c6-9, Socrates does not refer to the teleological $\alpha i \tau i \alpha$ but to the $\alpha i \tau i \alpha$ that will be provided by a stronger 'Atlas' (99c4-5). This means that the passage offers no evidence that Socrates abandons teleology or modifies his views about it. He acknowledges, instead, that he could not find or learn any $\alpha i \tau i \alpha$ stronger than the teleological one. This, I suggest, allows an interpretation of the Phaedo in which Socrates offers a consistent account of the aiti $\alpha$ of generation and destruction. 


\section{Teleological Causation}

In Plato, the terms $\alpha i \tau i \alpha$ and $\alpha_{i}^{\prime} \tau$ iov are often taken as synonyms and translated as 'cause' or 'explanation.' In the Phaedo, however, Plato seems to distinguish them. ${ }^{1}$ This difference has been characterised in various ways, but the basic idea is that an $\alpha i \tau i o v$ is what is responsible for something, and an $\alpha i \tau i \alpha$ is whatever links the $\alpha i \tau i o v$ to its deed assigning the responsibility. In other words, one points to the relata, and the other to the relation. In particular, Socrates refers to nous ('intelligence')

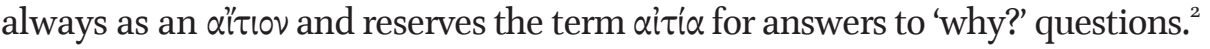

I use the terms 'teleology' and 'teleological $\alpha i \tau i \alpha$ ' to refer to the thoughts introduced by Socrates at $97 \mathrm{~b} 8-98 \mathrm{~b} 6$. The main claim there is that if there is a nous that orders everything, it does it in whatever way is best (97c4-6). This includes both a reference to an agent, nous, that does the ordering, and to an end, the best order

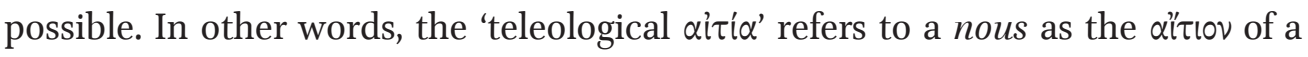
deed, which is the order caused by nous. Abusing Aristotelian terminology, what I call the teleological $\alpha i \tau i \alpha$ in the Phaedo, at least in its original formulation, includes an efficient and final aspect. ${ }^{3}$

Socrates refers back to this teleological $\alpha i \tau^{\prime} \alpha$ in $99 c 1-3$ and $99{ }^{-} 5^{-6}$ to criticise the views of some of his predecessors (see T1 below). The context is a passage that

${ }^{1}$ Otherwise passages like Phd. $97 \mathrm{c}$ do not seem to make sense. Compare Phd. 99b6-c2 with Cra. 413a4-5; Phlb. 26e3-27a9, 3od3, and especially 3oc4-7; Phd. 11oe2-6; Resp. 379c3, 329d3, 468a8; Ti. 18е3, 29d6, 33a6, 38d7, 4ob4, 44c7, 47b6, and 63e; Phdr. 229е5-23оa6, Leg. 896b1 and 967c5; and $\mathrm{Grg} .457 \mathrm{a3}$.

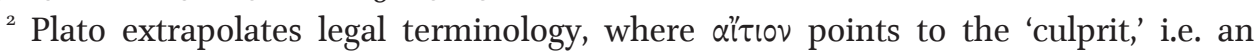
object, person or state of affairs qua responsible for something, and the aiti $\alpha$, which refers to whatever makes the 'accusation' againts the culprit, meaning the object (e.g. murder weapon) or causal account that links the culprit with his or her deed. Notice that in the way I am characterising the distinction, I am not assuming, like M. Frede (1980) 233 and J. G. Lennox (1985) 199, that the use of these terms imply a sharp distinction between entities and propositional items, but between whatever is held responsible for an effect and whatever connects the effect with what was responsible for it, regardless of their ontological status. Nor am I assuming that this distinction holds in all dialogues. The extrapolation of legal terminology could be endemic to the Phaedo. Moreover, Plato's formulations may sometimes be elliptic, prolix, or metaphorical, which explains why the distinction is not always clear. For the discussion see G. Vlastos (1969) 292-96, T. H. Irwin (1983) 130-32, A. Silverman (1992) 99 n. 32, D. Sedley (1998) 114-15, R. J. J. Hankinson (1998) 84-85, I. Mueller (1998) 83-84, G. M. Ledbetter (1999) 257-258, M. Ferejohn (2006) 151, D. Wolfsdorf (2005), and R. Sharma (2009) 137 n. 1.

${ }^{3}$ Occasionally scholars use 'teleological' simply as interchangeable with Aristotle's final $\alpha i \tau i \alpha$, and here I am using it in a sense that includes a goal and a mover. For a recent survey on ancient teleology see J. Rocca (2017). 


\section{Teleology and causation in the Phaedo}

runs from 99 b6 to d2, which immediately follow Socrates' criticism of Anaxagoras' account (98b7-99b4). First, Socrates introduces the two theories and accuses them of making the same mistake as Anaxagoras -i.e. confusing the real $\alpha i t i o v$ with what is necessary for something to be an ailiov. Then, he adds a more general criticism against these theories. Next, Socrates announces his own general proposal, labelling it a $\delta \varepsilon v ं \tau \varepsilon p o \varsigma ~ \pi \lambda \circ \hat{\varsigma} \varsigma$ ('second sailing,' 99c6-d2). ${ }^{4}$ The accounts introduced in the first section of the passage have received relatively little attention but the latter is a locus classicus that has been widely discussed. ${ }^{5}$ The Greek reads as follows:

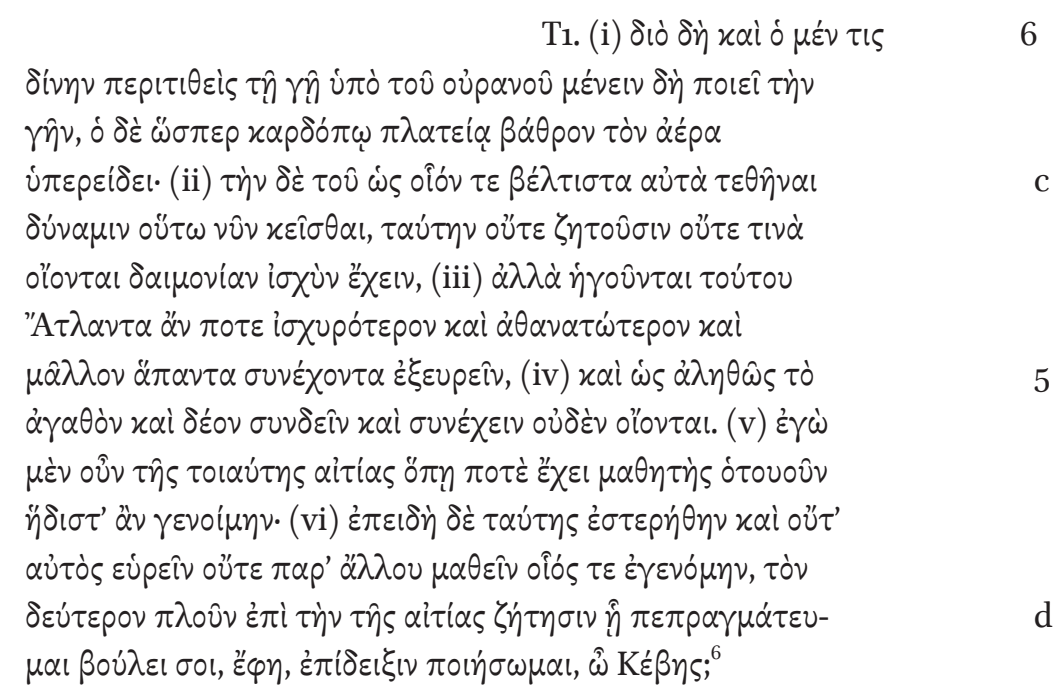

The text can be translated as follows:

(i) That is also why one person surrounding the earth with a vortex makes it stay under the heavens, while someone else puts air under it as a base as if the earth were

${ }^{4}$ For the discussion of the translation and interpretation of this locution, see note 23 .

${ }^{5}$ For the first section see J. T. Bedu-Addo (1979), D. Sedley (1989), C. J. Rowe (1993) 237-38, A. Gregory (2001) 84-86, and A. Mason (2013) 206-8. But notice how K. Dorter (1982) 117-20, D. Bostock (1986) 142-46, and H. H. Benson (2015) 103, 192 skip sentence (i). The interest in the second part of the passage goes back to Aristotle (Gen. corr. 2.9, 335b917, 18-23; Metaph. 1.9, 991b1-9; cf. 13. 5, 1080a) but recent discussions can be traced back to the end of the ninetieth century.

${ }^{6}$ Greek edition by E. A. Duke, W. F. Hicken, W. S. M. Nicoll, D. B. Robinson, \& J. C. G. Strachan (1995). 
a flat kneading-trough. ${ }^{7}$ (ii) As for their capacity for being in the best place as they are now, this they do not look for nor do they believe it bears any divine force, (iii) but they suppose they might discover an Atlas stronger and more immortal than this that holds everything together, (iv) and they do not believe that the good and binding truly binds and holds anything together. (v) Now I would most gladly become anyone's student to learn what is such aitía. (vi) However, since I was deprived of it and was not able either to find it myself or to learn it from someone else, would you like me to give you a presentation, Cebes, of how I pursued my second sailing in search of the $\alpha i \tau i \alpha{ }^{8}$

Today, many scholars agree that this passage signals an abandonment of the teleological $\alpha i \tau i \alpha$, in favour of a new type of formal $\alpha i \tau i \alpha$. Paul Shorey $(1888,406$, $1933,179)$ and N. R. Murphy $\left(1936,1951,145^{-48}\right)$ introduced this reading, but it was not until the second half of the twentieth century that it became predominant. I shall call it the 'non-teleological reading.' Consider, for example, the confident remarks of one of its most influential advocates, Gregory Vlastos (1969) 297-298: ${ }^{9}$

T2. Note that the reference of $\tau \alpha v^{\prime} \eta \zeta$ in C8 (the object of $\dot{\sigma} \sigma \varepsilon p \eta \dot{\theta} \eta \eta v$ and also, with the im-

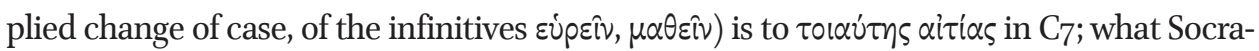
tes has failed to discover by his own labours or from those of others and is prepared to do without for the present is the teleological $\alpha i \tau^{i} \alpha$ itself. This leaves no room for understanding him to mean (as has been done over and over again in the literature) that his 'second-

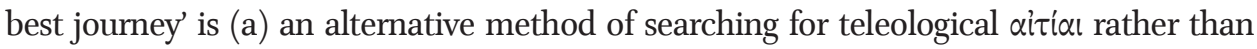
(b) an alternative method of searching for aitial. The text offers no direct support for (a), since nothing is said of different methods of looking for teleological aitial (the natural philosophers were condemned for failing to look for such $\alpha i \tau i \alpha$, not for looking for them by the wrong method).

Although the non-teleological interpretation has been so successful that it is often taken as the default reading of the passage,${ }^{10}$ not everybody is convinced that the

${ }^{7} \mathrm{~J}$. Burnet (1911) 107 suggests reading $x a p \delta 0 \pi i \omega$, the lid of a kneading-trough, instead of $x \alpha \rho \delta \delta \delta \omega$, as a more plausible candidate for something being supported by air. See also A. Gregory (2016) 148.

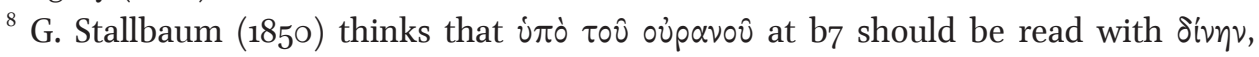

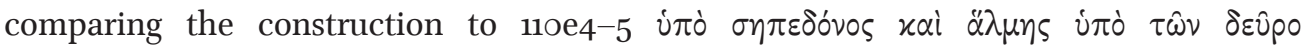

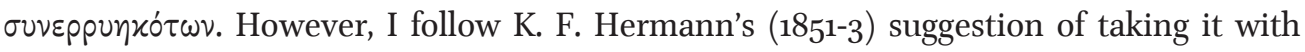
$\mu \varepsilon \dot{v \varepsilon}$ เv. See also W. D. Geddes (1863), R. D. Archer-Hind (1883), H. Williamson (1904), and J. Burnet (1911).

${ }^{9}$ See also P. M. Huby (1959), C. C. W. Taylor (1969) 45-59, E. L. Burge (1971), and C. Stough (1976).

${ }^{10}$ Take for example J. Annas (1982), K. Dorter (1982) 120, D. L. Ross (1982) 23-25, J. G. Lennox (1985), D. Bostock (1986), F. Fischer (2002), S. Kelsey (2004) 38-39, M. N. Byrd (2011) 148, A. Mason (2013), D. Ebrey (2013), and H. H. Benson (2015) 92-112, 191-92. 
abandonment of teleology is definitive. ${ }^{11}$ Moreover, the idea that, in the Phaedo, Socrates does not completely give up on teleology—call this the 'teleological interpretation'- has always had a significant support. ${ }^{12}$

One common complaint is that the non-teleological interpretation ignores the wider context of the passage. It has been argued, for example, that such an interpretation makes Socrates abruptly change the original topic of discussion from the $\alpha i \tau i \alpha$ of generation and destruction (95-96a) to one about formal $\alpha i \tau i \alpha$. Yet, Socrates had announced the need for a thorough and exhaustive investigation into the former (95e1o-96a1), something that is left incomplete if there is an abandonment of teleology. There are also various ways to understand the second sailing as including a teleological component. For example, David Sedley (1998) 126-27 thinks that the teleological causation is just a special application of the formal

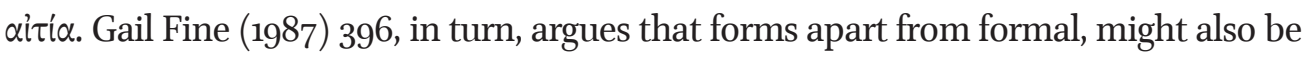
final $\alpha i \tau i \alpha$.

A second objection against the non-teleological interpretation consists in arguing that T1 offers evidence to think that Socrates is not completely deprived of the teleological $\alpha i \tau i \alpha$. One reason to think this is that $\dot{\omega} \varsigma \dot{\alpha} \lambda \eta \theta \hat{\omega} \varsigma$ at 99c5 suggest that Socrates already knows 'the good and binding. ${ }^{13}$ Another reason, perhaps the most influential observation against the non-teleological reading, is a remarkgiven first by J. T. Bedu-Addo (1979) 105-6 and later by David Wiggins (1986) 3-

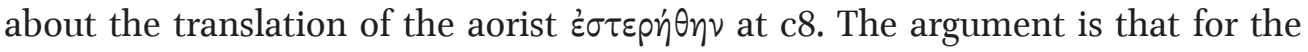
non-teleological reading to work, the text would require a perfect tense (i.e.,

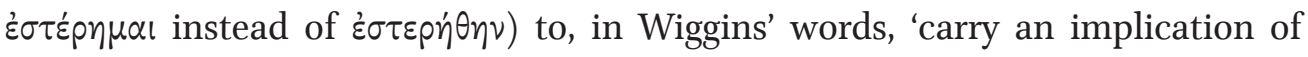
resignation or acquiescence.' However, they argue, in the aorist, this connotation is not present. Therefore, Socrates says only that at the time, he was denied the teleological $\alpha i \tau i \alpha$, not that it was permanently out of his reach. As a consequence, they think that it is perfectly possible to understand the second sailing as a fresh start in the search for the teleological $\alpha i \tau^{i} \alpha$ or at least as a proposal that is not completely divorced from a teleological component.

However, I think that these arguments against the non-teleological reading can be resisted. First, Vlastos and others were completely justified in translating the aorist ¿ं $\tau \varepsilon \rho \eta \dot{\theta} \theta \nu$ as a perfect. As Herbert W. Smyth (1956) 432-433 puts it, 'In the Greek the aorist, which simply states a past occurrence, is often employed where English uses

\footnotetext{
${ }^{11}$ See, for instance, M. M. McCabe (1998) and C. J. Rowe (1993) 237-39.

${ }^{12}$ See, for instance, E. Zeller (1922) II, i, 687, n. 1, R. S. Bluck (1955) 13-16, 111-13, 160-73, 198-200, (1957) 21-31, I. M. Crombie (1963) 161, T. Gould (1963) 77, M. J. Cresswell (1971), D. Gallop (1975) 146-47, J. T. Bedu-Addo (1979), G. Fine (1987), D. Sedley (1989; 1998), D. Wiggins (1986), Y. Kanayama (2000) 87-100, and A. Gregory (2001) 85-87.

${ }^{13}$ See J. T. Bedu-Addo (1979) 106.
} 
the perfect denoting a present condition resulting from a past action [...] the aorist may be translated by the perfect when the perfect has the force of a present.. ${ }^{14}$ Second, $\dot{\omega} \varsigma \dot{\alpha} \lambda \eta \theta \hat{\omega} \varsigma$ at $99 c_{5}$ does not really imply that Socrates knows the good and binding. If $S$ reports that $P$ does not believe that $x \dot{\omega} \varsigma \dot{\alpha} \lambda \eta \theta \omega \varsigma y$, this does not imply that $S$ believes it does.

Moreover, if some teleological component survives in the formal $\alpha i \tau^{i} \alpha$ of the second sailing, it is only in a tenuous way since there is no explicit reference to a teleological agent after $\mathrm{T} 1$, and even if there are some other teleological elements in it, a non-teleological reading of T1 could still stand. This is so, because it is possible, for example, that Socrates is only abandoning the specific type of teleological $\alpha i \tau i \alpha$ he introduced at the beginning (97c4-6).

Finally, to the complaint that the non-teleological reading implies a sudden change of topic, it could be argued that Socrates' announcement of the need for an exhaustive and thorough investigation does not commit him to offering any conclusions. Besides, although forms are not the $\alpha i \tau i \alpha$ of generation and destruction they were part of Socrates' investigation into this topic, and crucially, turned out to be the piece of the discussion that offered 'something useful' (96a2) to answer Cebes' objection (86e-88b), which is what prompted the whole autobiographical passage.

Unfortunately, the non-teleological reading is still unsatisfactory in certain respects. First, because even if there is a way to justify the change of topic, it might still seem disappointing that Socrates would fail to provide at least a basic sketch of the $\alpha i \tau i \alpha$ of generation and destruction, particularly after so long a discussion into the topic. Second, a Socratic abandonment of the teleological aitía seems suspiciously out-of-character, especially if we take into account the dramatic setting: the last hours of Socrates' life. Moreover, elsewhere in the Platonic corpus and in Xenophon, Socrates seems always fully committed to teleological $\alpha i \tau i \alpha$ and agents. ${ }^{15}$ In no other place Socrates' makes reference to a period of his life when he abandoned teleological aitia. Finally, as I show in the next section, the standard reading often glosses over and dismisses the careful discussion of those

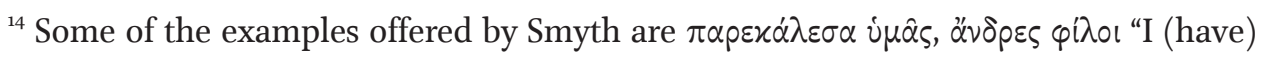

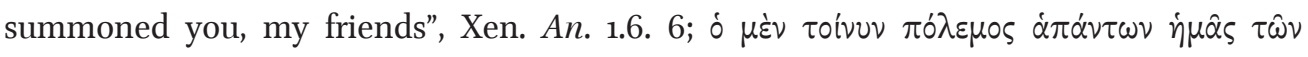

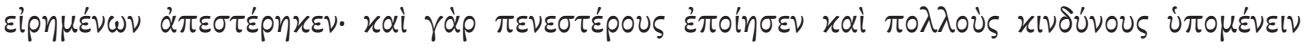

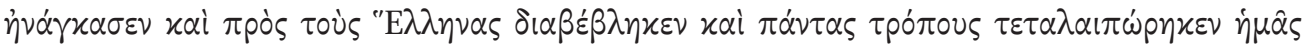
"now the war has deprived us of all the blessings that have been mentioned; for it has made us poorer, compelled us to undergo many dangers, has brought us into reproach with the Greeks, and in every possible way has caused us suffering", Isoc. 8. 19; and

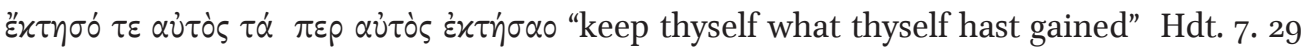
(Smyth's translations).

${ }^{15}$ See, e.g. Philebus 23b5-27c2, 30a9-e3; Republic 6 and 10; Xen. Mem.1.4 and 4.3.
} 
who posit $\alpha i \tau i \alpha$ for the stillness of the earth at 99c1-6. Yet, Socrates' criticisms to these views depends on a contrast that assumes he is as committed to the teleological $\alpha i \tau i \alpha$ as ever.

These complaints do mean that the non-teleological reading is not, strictly speaking, a valid reading of the Greek and even a plausible philosophical interpretation. The question, however, is whether it is the best one. My suggestion is that we can do better.

In the next sections I argue for a more radical teleological reading of $\mathrm{T} 1$ and explain some of its advantages. I start by rejecting the widespread assumption

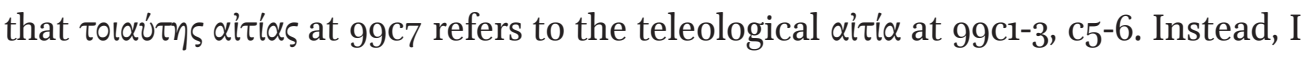
argue, it refers to the $\alpha i \tau i \alpha$ at 99c4-5. As I mentioned at the beginning, this means that the passage does not imply an abandonment of teleology at all or of any kind (not even partial or temporary, as in previous teleological interpretations). This new reading, I argue, avoids the objections to previous teleological readings and preserves all the advantages of the non-teleological reading. Furthermore, it enables an interpretation where Socrates succeeds in providing an interesting causal account of generation and destruction.

\section{A Problematic Assumption}

Everyone I am aware of, regardless of the interpretation they support, assumes that

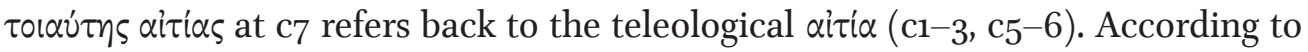
this view, Socrates would have gladly become a student of anyone with such knowledge of teleology, but could not find anyone. For this reason, he went on to propose a second sailing in the search of the aiti $\alpha$. Whether there is a complete and definitive abandonment of teleology or not may be a debated issue, but everyone concedes that Socrates says he abandoned the teleological $\alpha i \tau i \alpha$ he was looking for. I thus call this the 'traditional reading' of T1.

However, I will show, if this reading were correct, Socrates would be simultaneously undermining his own criticism to the theories found in T1-which I will call the 'Atlas theories'-and making an unmotivated concession. And as a result, Socrates fails to properly motivate the need for his second sailing.

First, I will explain why in the traditional interpretation Socrates is undermining his own criticism to the Atlas theories. In the sentence immediately preceding his alleged abandonment of teleology, Socrates describes the Atlas theories and its $\alpha i \tau i \alpha$ l

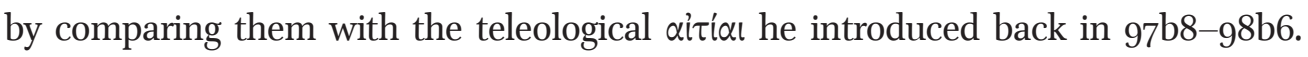
Socrates' reference to Atlas, a titan of the pre-Olympic era, is a good indication of the strong contrast between the two aitial. Atlas is the god of astronomy who defied Zeus in the Titans' revolt, and after the Olympic gods won, was condemned to hold up the 
sky for all eternity. ${ }^{16}$ This suggests that the teleological nous is an Olympic, heavenly, divine force, whereas the power of Atlas is, on the contrary, brute and physical. By comparing the missing ail $\tau$ เov with Atlas, Socrates is implying that those who look for it are joining forces with the loser's side. At the end of the Titanomachia, it was Zeus who commanded Atlas to hold up the heavens, so in reality his decision is behind Atlas' labours too. Thus, the mythological reference signals that those who have abandoned and remain unconvinced about teleology are the Atlas theorists, which fool themselves thinking that they will find a champion to overthrow the divine order imposed by nous. ${ }^{17}$

With this in mind, take a look again to 99c1-6 (in T1). The sentence is a compound with three independent clauses (ii-iv). I quote the lines again:

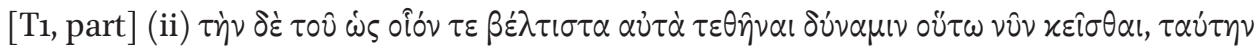

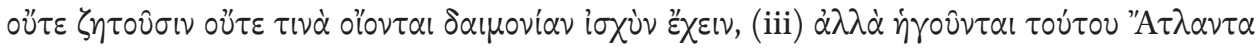

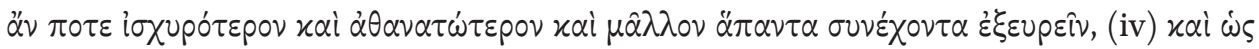

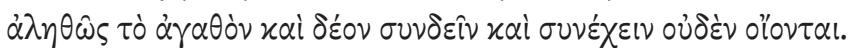

(ii) As for their capacity for being in the best place as they are now, this they do not look for nor do they believe it bears any divine force, (iii) but they suppose they might discover an Atlas stronger and more immortal than this that holds everything together, (iv) and they do not believe that the good and binding truly binds and holds anything together (99c1-6).

In the first and last clause (i.e., ii and iv), Socrates points out that the authors of the Atlas theories do not care about or believe in his teleological ai í $\alpha$. The middle adversative clause (iii) tells us, instead, that they believe in a different $\alpha i \tau i \alpha$, which

${ }^{16}$ Hesiod describes Atlas' punishment as follows: 'Iapetus married Clymene, Ocean's beautiful-ankled daughter, and went up into the same bed with her. She bore him Atlas, a strong-hearted son [...] And by mighty necessity Atlas holds up the sky with his head and with his tireless hands, standing at the limits of the earth in front of the clear-voiced Hesperides; for this is the portion which the all-wise Zeus assigned him.' Hes. Theog. 507-20; transl. G. W. Most (2006) with minor modifications. See also lines 746-5o, Hom. Od. 1.52-4, and Aesch. $P V$ 347-20, 445-30. Pindar, in turn, describes the scene as follows: "The cruellest thing, they say, is to know the good but to be forced to stand apart from it. And in truth he, like Atlas, now struggles under the weight of heaven, far from his own land and possessions; and yet immortal Zeus set the Titans free again.' Pind. Pyth. 4.286-92; transl. A. Verity (2007).

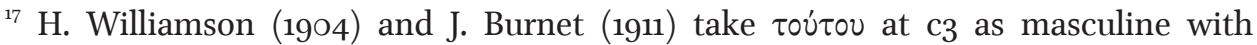
reference to Atlas. Hence, they translate 'an Atlas stronger and more divine than the true Atlas.' This other 'true Atlas' would be the teleological airi $\alpha$. However, this makes the

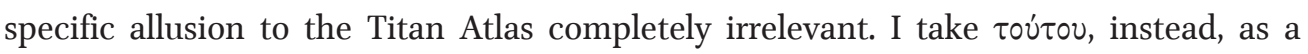

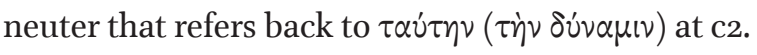


they have not yet discovered, but that will be stronger and more permanent than what teleology has to offer.

Given this contrast between the teleological $\alpha i \tau i \alpha$, the Atlas theorists' scepticism towards it and their supposition that they will find another type of $\alpha i \tau^{i} \alpha$, it would not make any sense for Socrates to abandon his own teleological proposal in the next sentence. It would be like someone who proposed a search party for a missing person, criticised those who did not want to join the search, only to abandon the effort immediately after. Socrates criticism of the Atlas theories hangs on contrasting their general views with his own teleological proposal.

Moreover, an abandonment of the teleological $\alpha i \tau i \alpha$ in T1 would mean an unmotivated concession made completely out of the blue. None of the criticisms against Anaxagoras reject Socrates' idea that if there is a nous, it orders in whatever way is best. Anaxagoras simply does not seem to share such a teleological premise, but neither does he prove, show or give Socrates reason to think that things are not ordered in whatever way is best. All Anaxagoras does is to talk about other $\alpha^{\prime \prime} \tau \iota \alpha$, which Socrates rejects. Now, one could say that Anaxagoras certainly deprived Socrates of many of the teleological $\alpha i \tau i \alpha$ he wanted to learn, for instance, those concerning the celestial bodies, but it simply does not follow from there that there should be an abandonment of the teleological $\alpha i \tau i \alpha$ in general or of the specific version proposed by Socrates. Thus, if Socrates abandons teleology, he behaves like a student who abandons algebra because he had a disappointing experience with his first teacher. Besides, there is evidence that Socrates found at least two successful teleological

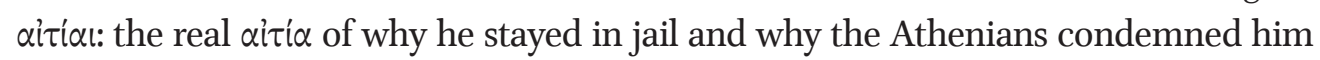
(98e1-99a4; $\mathrm{T}_{4}$, quoted in p. 100 in the last section). Socrates shows no doubts or reservations when conversing with his friends in prison, in thinking that the Athenians thought that it was better to condemn him, and that as a result he thought it was better, that is, more just, to stay and suffer the penalty imposed. He also uses these cases

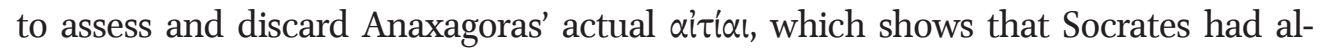
ready found some teleological $\alpha i \tau i \alpha$ at the time he first assessed Anaxagoras. As a consequence, it would be inaccurate for him to say he was deprived of the teleological $\alpha i \tau i \alpha$ in general or that he was not able to find any. If this were true, at the very least, Socrates would have needed some clarificatory note. Yet, he says nothing. ${ }^{18}$

\footnotetext{
${ }^{18}$ That the Socrates prison example counts as a successful teleological $\alpha i \tau i \alpha$ might be deemed controversial. One could object that Socrates' nous is not ordering everything or that his actions only involve what he thinks is best and not what is actually best. However, this objection assumes that 'everything' ( $\pi \dot{\alpha} v \tau \alpha)$ in $97 \mathrm{c}$ means 'everything at once'. Yet, the following lines (see $\tau \dot{\alpha} \pi \rho \dot{\gamma} \gamma \mu \alpha \tau \alpha$ at $98 \mathrm{c} 1$ and $\pi \varepsilon \rho \dot{~} \dot{\varepsilon} x \dot{\alpha} \sigma \tau 0 v$ at $97 \mathrm{c} 7$ ) suggest a weaker reading of 'everything', where nous orders 'each concrete thing separately' (for $\pi \dot{\alpha} v \tau \alpha$ to clearly mean 'everything at once' the text would require a $\alpha \mu \alpha$ that is not in the Greek). Concern-
} 
Finally, given that the traditional reading leaves the general views of the Atlas theories unchallenged, Socrates fails to reject the Atlas theories. Thus, he does not have enough grounds to motivate his second sailing, which is presented as a last resort. Consider it in this way. The Atlas theorists' wariness about 'the good and binding' raises a fair question. Why is nous and a teleological account of its capacity better than a simpler, non-teleological, account of the workings of the cosmos? ${ }^{19}$ Why should we assume that Socrates' teleology is more explanatory in general if, so far, it seems its success is limited to the human sphere?

If, so far, Socrates' teleological project is unable to account for natural phenomena where humans are not involved, it might be a good idea to abandon it in favour of the hope of a more conservative solution to the problems of the natural inquiry tradition. The Atlas theorists' promise is that the Atlas will offer a more general, permanent, and tight account of generation and destruction, which will provide stable knowledge and universal explanations without having to assume Socrates' teleology. In the traditional reading of the passage, however, Socrates does not explain why this was not a valid alternative for him and he offers no counterargument. ${ }^{20}$

All this raises a question: if the traditional reading is so problematic, why is it unanimously assumed as correct? The answer is threefold. First of all, it is a

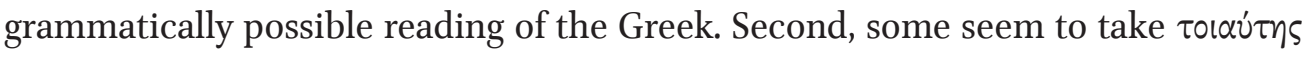
$\alpha i \tau i \alpha \varsigma$ to refer back, not to all the elements of the teleological $\alpha i \tau i \alpha$, but specifically to

ing what the best is, $97 \mathrm{c}$ leaves open the question on whether it is best for each thing, the whole or both. We get no indication about for whom it is best, or if the ordering is the best simpliciter. Another way to resist the prison example as a successful teleological airi $\alpha$ is to argue that in $97 \mathrm{c}$ Socrates is only referring to a concrete cosmic nous and not to the universal concept, which would apply to all types of nous. This is not an uncommon interpretation. See D. Bostock (1986) 143, D. Sedley (2007) 88 and A. Mason (2013). However, scholars reading the text in this way are forced to say that Socrates' explanation of his nous as the thing responsible for his staying in prison is some kind of analogy. Yet, the text does not present human nous in this way at all.

${ }^{19}$ In fact, the Atlas theories do not need to be completely free from teleology, only from the type of teleology proposed by Socrates. A teleology based on order or functions that do not mention the agent's intentions may be compatible with their research programme. For different senses of teleology in this context, see M. M. McCabe (2000) 185-93.

${ }^{20}$ One might object that since the Atlas theorists made the same mistake that Anaxagoras did, from the start we know that these theories cannot be the source of the knowledge that Socrates is looking for. Therefore, there is no need for him to reject their hope of finding a stronger Atlas. Reading the text in this way, however, cannot account for 99c1-6. To reject the Atlas theories, it would be enough to know that they offer a vortex and air as aitial of the stillness of the Earth. There would be no need to describe them any further. 
the good and binding, which they take, in turn, as a direct reference to the form of the good in the Republic. And if that were right, it would be plausible to think that Socrates could deny knowledge of such form, even if he does not really mean it. Finally, the traditional reading is attractive because, in it, Socrates may be changing or broadening his discussion from the search of the $\alpha i \tau i \alpha$ of generation and destruction to a more general search for $\alpha i \tau i \alpha$. This would, at least to some extent, fend off the text from Aristotle's seemingly demolishing criticism that in the Phaedo forms are posited as adequate $\alpha i \tau i \alpha$ of generation when that is clearly wrong (I shall come back to this point in the next section). ${ }^{21}$

Of course, that the traditional reading is grammatically possible does not mean it is the only one, or that, given the specific context, is the one that makes more sense. For instance, the good and binding seems more plausibly an epithet for Socrates' teleological nous (98a7-9), than a reference to the form of the good. Moreover, although it is true that the traditional interpretation is a better option than

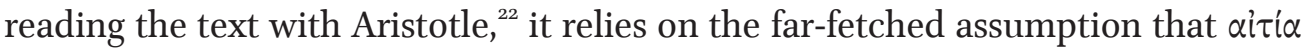
at $99 \mathrm{~d} 1$ is a cue for a more general discussion on causation rather than a reference to the original search for the $\alpha i \tau i \alpha$ of generation and destruction as we would expect given the context.

To all this one may wonder if it is possible to read the text in a way that avoids Aristotle's objection but also the problems of the traditional reading. In what follows, I will provide such a reading. To show this, I first explain and defend my interpretation of the Greek text. Then, I explain how in my proposal, Socrates incorporates the general views of the Atlas theorists into the discussion. Finally, I explain how my reading does a better job at shielding the text from Aristotle's objections and opens new directions for understanding the 'second sailing.'

\section{A Reference to the Missing Atlas}

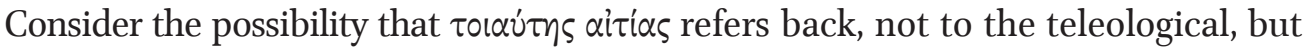
to the $\alpha i \tau i \alpha$ that the Atlas theories suppose they might discover (99c3-5). Taken in this way, Socrates says that he would have gladly become anyone's student to learn what this missing Atlas is, something that, if found, would allow a more superior $\alpha i \tau^{i} \alpha$ than the teleological one. Thus, in this reading, Socrates is not abandoning teleology at all, but rather is conceding the counterfactual that if the Atlas theorists could deliver the knowledge of their Atlas, he would be happy to learn

\footnotetext{
${ }^{21}$ See Arist. Gen. corr. 2.9, 335b9-17, 18-23; Metaph.1.9, 991b1-9, see also 13.5, 108 oa.

${ }^{22}$ Aristotle's reading is not impossible or even implausible, but I take it that it is not the most charitable. For a defense of Aristotle's reading of the Phaedo see J. Annas (1982).
} 
from them. But since that has not happened, and Socrates has not been able to find a stronger $\alpha i \tau i \alpha$ than the teleological one, that door remains closed.

The proposal offers some advantages over previous teleological readings. First, the translation of $\dot{\varepsilon} \tau \varepsilon \rho \dot{\theta} \theta \eta \nu$ at $c 8$ is no longer a problem. Even if translated as a perfect, it does not refer to the teleological $\alpha i \tau^{i} \alpha$, but rather to the promised Atlas. Moreover, since read in this way, there is no evidence of Socrates abandoning, or modifying his views on teleology, the lack of explicit mentions of it in the second sailing need not be a problem; it could just mean that the original formulation of teleology is implied throughout the entire section. ${ }^{23}$

I shall come back to the last point later, but first notice that nothing really pre-

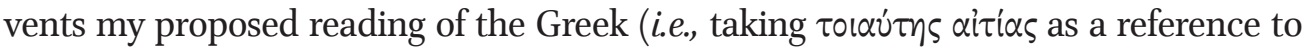

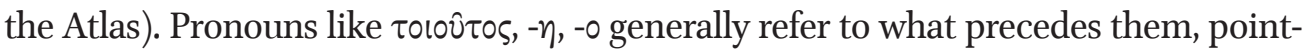
ing to something near in place, time or thought. But, as I have noted, in our passage, the sentence that runs from 99c1-6 is a compound with three independent clauses,

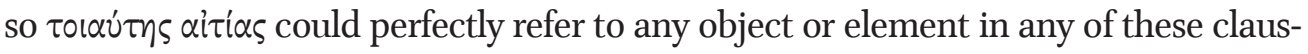
es. Now, the most proximate element it can pick up is the good and binding, but that, as I have argued, would put Socrates in a difficult spot. ${ }^{24}$ Thus, it makes better sense that Socrates refers to the knowledge of the Atlas, since in this way Socrates would not undermine his contrast and criticism of the Atlas theories.

What distinguishes the Atlas theorists from other natural inquirers is their interests in finding a definitive answer for the generation and destruction of things. They believe they will discover something that holds everything together. In contrast, their answers to explain the stillness of the earth are unoriginal. More than one posited air or vortex to explain why the earth stays in its place. But it is novel and striking that they are explicitly unpersuaded and uninterested on teleological $\alpha i \tau i \alpha \iota$ and its divine

\footnotetext{
${ }^{23}$ One might wonder how this interpretation sits within the discussion of the meaning of $\delta \varepsilon v ं \tau \varepsilon p o \varsigma ~ \pi \lambda \circ \nu \hat{\varsigma}$ (translated here as 'second sailing'). This locution has been taken to mean either second-best method of inquiry or an answer to the $\alpha i \tau i \alpha$ of generation and destruction or both. But it has also been taken to mean 'second attempt', without any negative connotation (or second-best, only ironically). For a recent discussion and relevant literature, see H. H. Benson (2015) chap. 4. I would argue that my reading of T1 is compatible with both translations and at least some of the options above. In the next section, however, I suggest it could also mean a second attempt at investigating the $\alpha i \tau i \alpha$ of generation and corruption, which consists of connecting the teleological agent with its deeds. Then the first sailing would be Socrates' attempt at learning it from someone else, whereas the second one is Socrates showing how he found the knowledge on his own.

${ }^{24}$ Moreover, the pronoun $\tau 0100$ tos does not need to pick up the most proximate element. See, for example, $\tau 01 \alpha \hat{\tau} \tau \alpha$ at 99 a 5 .
} 
source, while believing that they will be eventually able to provide better answers. ${ }^{25}$ If they could deliver their promise, it would be a remarkable contribution, even if they have inadequate terminology when it comes to the details. But all this is unproblematic in my reading of sentences (v) and (vi) since, Socrates would simply concede that he is open to learn from such remarkable knowledge that no one has yet found.

The Atlas theorists seem to be taking their hope in the missing Atlas as a working hypothesis. This explains why they are unpersuaded about teleology and offer non-teleologial $\alpha i \tau^{i} \alpha$. Their argument could be reconstructed as follows:

a. There is an Atlas stronger and more immortal [than the things' capacity of being in the best place] to hold everything together (iii; 99c3-5) (Assumption).

b. If that is so, then there is no need to believe that the good and binding (i.e., nous) truly binds and holds things together (iv; 99c5-6).

c. If there is no need to believe that the good and binding truly binds and holds things together, then there is no need either to look for the things' capacity of being in the best place as they are now or to think this capacity bears any divine force (ii; 99c1-3).

d. If there is no need to either look for the things' capacity of being in the best place as they are now or think this capacity bears any divine force, then either a vortex surrounding the earth keeps it under the heavens or air is under the earth as a base as if the earth were a flat kneading-trough (i; 99b6-7).

e. If there is an Atlas stronger and more immortal [than the things' capacity of being in the best place] to hold everything together, then either a vortex surrounding the earth keeps it under the heavens or air is under the earth as a base as if the earth were a flat kneading-trough (HS from b-d).

f. Therefore, either a vortex surrounding the earth keeps it under the heavens or air is under the earth as a base as if the earth were a flat kneading-trough (MP from a, and e).

\footnotetext{
${ }^{25}$ Commentators usually suggest Empedocles and Anaxagoras as the possible authors of the Atlas theories (Arist. Cael. 30ob2-3, 295a9-21, 294b13-17). Other possible candidates include Anaximander (Simpl. in Cael. 2.13, 532, 13-14), and the atomists (Philoponus, in Phys. 262.8-13 and again Arist. Cael. 294b13-17). Anaxagoras himself talks about a vortex surrounding the earth and air supporting it (DK59A88; DK59B9; DK59A57; DK59A12; but see DK59A42). However, if 99c1-6 is taken into account, the most plausible reference is Aristophanes' Nubes (365-369, 379-381, 369-409, 826-828), and, indirectly, to some of the views ridiculed there, perhaps those of Diogenes of Apollonia (DK64A16a and B8; Simpl. in Phys. 153, 19-20) and Archelaus of Athens (DK6oA1 and A12). However, I will leave the discussion of Plato's sources for another occasion.
} 
The aitial of the stillness of the earth hang on the possibility of finding a stronger answer to the general order of the cosmos than the one provided by strong teleological accounts. The Atlas theories assume the Atlas exists because it might seem the best explanation. After all, teleological $\alpha i \tau i \alpha \iota$ have been either unsuccessful or confined to the human sphere. The Atlas theories just point out that there are not sufficient reasons to accept teleological $\alpha i \tau i \alpha{ }^{2}{ }^{26}$ According to this reconstruction, Socrates has the burden of proof. The thought behind assuming premise (a) can be understood as an abduction:

Observation: There is order in the universe.

Hypothesis: A non-teleological Atlas explains this order.

Plausibility: A non-teleological Atlas is relatively more likely to be true, at least compared to the competing teleological hypothesis (given the present shortcomings of teleology).

Conclusion: A non-teleological Atlas best explains the order in the universe.

Therefore, assuming (a) is reasonable.

If this is the scenario, Socrates needs a counterargument to discredit and reject the Atlas theories and their hope. However, nothing he has said up to $99 \mathrm{C}_{5}$ offers this. Luckily, (v-vi) can be read-as I have proposed - as a rejection of this hope. Notice, however, that Socrates' complaint cannot simply be that the Atlas theorists have not yet found their Atlas. Their main argument $(\mathrm{a}-\mathrm{f})$ works just by assuming they might find it, something that seems reasonable given the dialectical context. Moreover, Socrates' own hopes (finding teleological $\alpha i \tau i \alpha$ to explain not only human actions but also natural phenomena) could be accused of the same problem. Thus, when Socrates says that he was deprived of the Atlas, unable to find it himself or

${ }^{26}$ Taken in this way, however, one may wonder whether Socrates' later argument at 108e-109a7 is not enough to reject the Atlas theories. Socrates' answer there (based on Anaximander's equipoise argument; see Arist. Cael. 2.13, 295b10-16=DK12A26; [Ps.-?] Hipp. Ref. 1.6.3 $\left.-7=\mathrm{DK}_{12} \mathrm{Au1}\right)$ is presented as more economical than the one offered by the Atlas theories, since it seems to require fewer elements to explain how the earth stays in its place. Moreover, it seems that an argument against the Atlas theories could be constructed: g. It is not the case that (f) (from 108e4-109a7). h. Therefore, it is not the case that (a) (MT from e, and g). But Socrates does not make this argument because, although persuaded by the equipoise argument, he admits he lacks knowledge about the matter. Thus, he is not really in a position to defend premise (g). Moreover, the equipoise argument would not answer what Socrates wants. The argument does not explain why the earth keeps still in the middle, only how this is possible. See C. J. Rowe (1993) $271-72$. See also D. Furley (1989) 17. For a teleological interpretation of the passage, however, see D. Sedley (1989) 364-65. In Plato, the equipoise argument is also found in Ti. 62d12-63a2. See D. Furley (1989) 17-18, 23-26, A. Gregory (2016) 147-49, and M. Schofield (1997) 46-48. 
learn it from another, this has to be taken as denying the Atlas theories' hopes; a direct challenge to premise (a). But since the reason Socrates offers to reject (a) is defeasible (someone can come and find the Atlas after all), he concedes the counterfactual: he would gladly become the student of anyone who possessed the knowledge of such a missing Atlas. ${ }^{27}$

Despite his best efforts, Socrates could not find a stronger $\alpha i \tau i \alpha$ than the teleological and nor could the Atlas theorists. There is not even a clear path or method to find the Atlas, there is only a hope, a supposition that there should be. So, without a breakthrough in this search, it is not even a research programme but only wishful thinking. Now, Socrates has explained that he was also unable to learn the teleological $\alpha i \tau i \alpha$ from someone else, and if he too had been unable to find it, both theories would be on equal footing. However, as I noted in the previous section, this is not the case. Socrates was able to find some teleological $\alpha i \tau i \alpha \iota$ himself, and even if they are restricted to human action, this success is enough to justify his hopes. From this it follows that the second sailing will show how Socrates found the aiti $\alpha$ of generation and destruction by his own efforts, and that this has to include or presuppose the original teleological $\alpha i \tau i \alpha$.

\section{The Cause of Generation and Destruction}

If Socrates has not questioned his previous views on teleology and the $\alpha i \tau^{i} \alpha$ in (vi) is that of generation and destruction, then the second sailing is not about a new standalone $\alpha i \tau i \alpha$ that fails to explain generation — as Aristotle wants us to believe. Instead, it is the last piece of a puzzle Socrates is putting together and which includes nous, its choosing of the best, and thing's participation in the forms. Let me outline this possibility.

First, notice that the introduction of forms does not exclude teleology. Socrates goes back to show how his new formal answers are safer than those offered by natural inquiry, which he cannot understand now, and he rejects. But if the teleological ordering of nous had been abandoned in the same way, one would expect Socrates to offer a similar comparison, examples, and explanations of how answers based on

${ }^{27}$ The argument against the Atlas theories can be understood as follows: (1) If Socrates is deprived of the Atlas (i.e., a), and he is neither able to find it himself nor to learn it from another, then, as things stand, Socrates cannot suppose he might discover it. (2) Socrates is deprived of the Atlas and he is neither able to find it himself nor to learn it from another. (3) Therefore, as things stand, Socrates cannot suppose he might discover the Atlas ( $M P$ from 1 , and $2 ;=\neg$ a). 
forms replace teleology or how teleological accounts confuse him, something we do not get. ${ }^{28}$

Now, Aristotle is right about a couple of things. Forms alone cannot account for generation. If that were so, they would generate in a continuous way. Put the other way around, forms do not really explain why this or that particular thing became or stopped having certain property at a specific time and place, but only why all things that have a property are the way they are. Aristotle is also right to point out that whatever is produced in something by the participation in the forms is not produced without an agent. In other words, forms alone cannot explain why Alcibiades in particular is beautiful but only why all beautiful things are beautiful. But none of these facts are a problem if my reading is correct. On the contrary, they become reasons to think that forms are meant to fit into a larger account that includes the previous remarks of a teleological nous; one that can really explain the generation and destruction of each particular thing.

One may still worry that there is a lot of room between what we can make of the textual evidence in the second sailing and my idea of a unified account that incorporates nous, its teleological activity and forms. In the second sailing, one may object, Socrates seems to offer an approach where forms monopolise the causal explanation. Take, for example, the famous passage, where Socrates describes his 'safest answer':

T3. Consider, he said, whether you also agree with me as to the following; for it seems to me that if something else is beautiful besides the beautiful itself, it is beautiful by no other reason than that each of these things participates in that beautiful, and I say so in everything.

-Do you agree with an $\alpha i \tau i \alpha$ such as this?

-I agree.

-Well then, he said, I no longer understand nor am I able to recognise those other ingenious $\alpha i \tau i \alpha$. But, if anyone tells me why something is beautiful either because it has a bright colour, or shape, or anything else such as these, I dismiss these other things. For I am confused with all these other things. But I simply, artlessly, and perhaps simplemindedly admit this to myself: that nothing different makes something beautiful than the beautiful itself, whether by its presence or by communion, or in whatever way it indeed happens. For I do not go as far as to affirm this ${ }^{29}$ with confidence, but only that it is through the beautiful that all beautiful things are ${ }^{30}$ beautiful. For I think this is the safest ${ }^{31}$

${ }^{28}$ Another helpful reminder that teleology has not been forgotten is the myth at $107 \mathrm{c}$ $115 \mathrm{a}$, which has a teleological structure. For an analysis of this passage, see D. Sedley (1989).

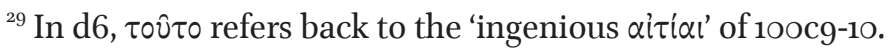

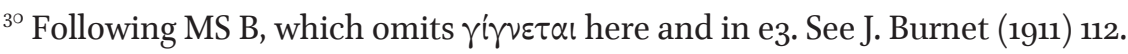

${ }^{31}$ Cf. 101a5-6. 
thing to answer to myself and to others; and I believe holding on to this I shall never be ruined; but this is the safe thing to answer for me and for anyone else, that it is through the beautiful that beautiful things are beautiful. Or do you not think so too?

-I think so (100c3-e4). ${ }^{32}$

A common way to express the formal causal principle (FCP) at play here is:

(FCP) If $X$ is $F$, then $X$ is $F$ because and only because $X$ participates (communes or holds some other relation) in the $F$-itself. ${ }^{33}$

Now, if this is the core payoff of the second sailing, it is easy to understand why some see a tension between Socrates' previous teleological commitments and this approach based on forms. It is not only that there is no explicit mention of nous and its choosing of the best. The problem is that it seems incompatible with Socrates' claims that if nous is the ali iov of each thing it orders in whatever way is best (97c36 ) and that there is no need to introduce any other $\alpha i \tau \iota \alpha$ (98a8-9; 99a4-5).

However, this objection can be rejected if, as I have suggested, the text distinguishes here between $\alpha i \tau i o v$ and $\alpha i \tau i \alpha$. If this is right, the claim that nous is the only aili $10 v$ is not threatened by the introduction of answers based on the FCP, because each of those are an $\alpha i \tau i \alpha$, but do not offer a new $\alpha i \tau i o v$ (Socrates may act justly because he partakes in justice itself, but he is still the only one responsible for his actions). Furthermore, there is no textual evidence that each form would count as a

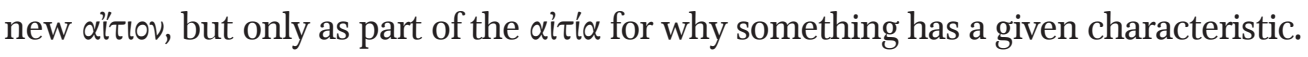
Otherwise, Aristotle would be right. A form cannot be the ail 1 iv of generation because they do not act or, if they do, they would continuously. ${ }^{34}$ Moreover, even in his introduction of the safe answer, Socrates seems to leave room for other elements apart from forms that explain how participation happens. When he says that only the beautiful itself makes things beautiful 'whether by its presence or by communion, or in whatever way it indeed happens' $\left(\operatorname{ood}_{5}-6\right)$, one inevitably wonders what exactly explains the form's presence in some objects and not others. But in my

\footnotetext{
${ }^{32}$ My translation, retaining $\pi$ poб $\varepsilon v o \mu \varepsilon$ vin at $\mathrm{d} 6$ with the MSS.

${ }^{33}$ Later, Socrates introduces safe, subtler, and more sophisticated answers (105b6-c7), which are meant to be more informative and observant of empirical evidence, but they ultimately follow this principle. For a discussion of whether these subtler answers count as proper aitía, see N. Denyer (2007) 93-94 and D. T. J. Bailey (2014) 25-26.

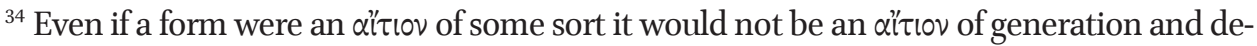
struction, and so not the same thing for which nous is said to be an ait tov. Socrates is committed to nous being the only aitrov of generation and destruction, which is compatible with the existence of formal, inefficient $\alpha i \tau^{\prime} \_\alpha$ of thing's characteristics in general. Moreover, there is no reason to think that the $\alpha i \tau i \alpha$ of generation and corruption cannot refer to forms and a teleological nous as two parts of a single account.
} 
interpretation he has already given the answer: it depends on the ordering of teleological agents able to think and modify their enviroment.

This still leaves us with a teleological and a formal $\alpha i \tau i \alpha$. Notice that both answer to a different 'why?' question. One answers to questions of the form 'Why did $S$ do $X$ ?' (Because $S$ thought $X$ was the best), whereas the other answers to questions like 'Why is $X, F$ ?' (Because $X$ partakes in the $F$-itself). However, none of these answers alone can explain why something comes to be, exists or is destroyed at a given time and place. On the one hand, a person always acts in a given way because she thinks that that was the best. But this does not explain why she thought a specific action was the best. The teleological $\alpha i \tau i \alpha$ l alone does not explain why nous would choose this rather than that as the best possible order for something. One may think about it in this way. If one asks, 'Why did Socrates stay in prison?' and obtains a simple, 'because Socrates thought that that was the best he could have done,' one could immediately reply, 'Sure! But why on earth did he think that?' The answer to that second question is required for answering the specific question and not something that applies to all of Socrates' actions. The reason is that unless one's choice of what is best (99a7-b2) is unpacked, there is an explanatory gap in the answer. Notice that Anaxagoras' philosophy is of no help with this problem because mentioning the necessary means for Socrates to stay in prison (bones and sinews) tells us nothing about why he thought staying was better than any other action within his reach, like escaping to Megara and Boeotia. In other words, why his specific decision was best.

On the other hand, as I have explained, a formal answer explains why any object with a given characteristic has such a characteristic but cannot explain why a specific object has it (or stopped having it) at a given moment and place. But if my reading is correct, Socrates assumes that to answer why each thing comes to be, exists, or is de-

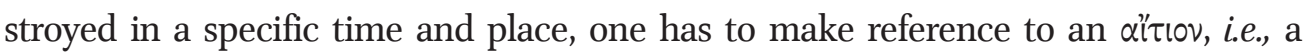
nous, and both a teleological and a formal aitial (distinguishing also that there are some things necessary for the $\alpha i$ i $\tau$ iov to be the $\alpha i$ iा $10 v)$.

I am not suggesting that a nous has to have direct access to the forms, though. Otherwise, only gods and philosopher rulers would count as causally efficacious. The requirement is weaker than that. Any nous, as far as it can think, chooses and acts for the best possible order. But the characteristics of the outcome of its action, whatever they are, can only be explained by participation or lack of participation in a specific form. However, the agent that brought about a specific state of affairs does not need to know this to succeed. If I want to warm up some water for my coffee, I do not need to know hotness itself nor even that fire always results in hotness. As an agent, I just have to believe that fire would warm water here and now, and that having a warm cup of coffee is the best possible thing to happen within my reach of action. But notice that if I want to fully explain why my cup is warm now and have a reliable meth- 
od to heat things, I need to know that fire always partakes in hotness, and that everything hot is hot through the hotness.

This model fits with what Socrates says about staying in prison. Until now, I have referred to this as a successful teleological $\alpha i \tau i \alpha$, but notice that in fact it offers more than that:

$\mathrm{T}_{4}$. Since the Athenians have decided that it was better to condemn me, on account of that I too have also decided that it is better to sit here, that is more just to stay put and suffer whatever punishment they decree. For by the Dog, I think these sinews and bones would long have been in Megara or Boeotia, transported by an opinion as to what is best, if I didn't think it more just to suffer whatever punishment the city imposes, rather than to escape and run away (98e1-99a4). ${ }^{35}$

Socrates is not only saying that he stayed because he thought it was the best thing to do; he is also explaining his thought process, the basis for his decision. He thought that staying was better because he thought it was more just to receive an injustice than to commit one. This is contrasted with the case that, if he had had the opinion (99a2) that it was better to run away, he would have done so. But in his case, the basis for his decision is a principle that he thinks is more just. To assess the outcome of his actions, we would have to ask if actions based on such a principle always partake in justice itself. But by contrasting the language of thinking with that of merely having opinions, Socrates implies that his principle of action is the correct one. Therefore, his explanation regarding why he stayed in prison includes revealing that he is responsible for such a state of affairs, and that his decision to stay was based on his thoughts about justice. If he brought about justice with his actions depends on whether his action really partook in justice itself.

Now, let me test this one more time with a different example. Socrates explains that he decided to stay in prison after the Athenians decided it was better to condemn him. So, one may wonder whether this model also explains the outcome of the Athenians' decision. When asked the question, 'Why did the Athenians condemn Socrates?' it seems obvious to answer that it was because they thought it was the best possible thing to do, so they did. Notice that my model is not committed to the idea that this was objectively the best possible decision. It only requires that a nous, or a group of them in this case, thought that was the case. This also means that even if the Athenians have done some wrong, the characteristics of the outcome of their action can still be explained with reference to the forms, things that always bear them, and their absence. They thought they were doing the best thing but since they were mistaken about what brings about justice, they put in action a plan that brought injustice instead. Thus, a unified reading of the $\alpha i \tau i \alpha$ of generation and destruction can explain

\footnotetext{
${ }^{35}$ Transl. D. Sedley and A. Long (2011).
} 
human failures like this one too. If we read $\mathrm{T} 1$ in the way I propose we can offer an interpretation in which Plato stays on topic and succeeds in offering a strong causal theory of generation and destruction. ${ }^{36}$

\section{REFERENCES}

Annas, J. (1982) "Aristotle on Inefficient Causes," The Philosophical Quarterly 32 (129), 31126.

Archer-Hind, R. D., ed. (1883) The Phaedo of Plato. 2nd (1894). London.

Bailey, D. T. J. (2014) "Platonic Causes Revisited," Journal of the History of Philosophy $5^{2}$ (1), $15^{-32}$.

Bedu-Addo, J. T. (1979) "On the Alleged Abandonment of the Good in the 'Phaedo'," Apeiron 13 (2), 104-14.

Benson, H. H. (2015) Clitophon's Challenge: Dialectic in Plato's Meno, Phaedo, and Republic. New York.

Bluck, R. S., ed. (1955) Plato's Phaedo. New York.

Bluck, R. S. (1957) “'Y

Bostock, D. (1986) Plato's Phaedo. New York.

Burge, E. L. (1971) "The Ideas as Aitiai in the Phaedo," Phronesis 16 (1), 1-13.

Burnet, J., ed. (1911) Plato's Phaedo. Oxford.

Byrd, M. N. (2011) "Dialectic and Plato's Method of Hypothesis," Apeiron 40 (2), 141-58.

Cresswell, M. J. (1971) "Plato's Theory of Causality: Phaedo 95-106," Australasian Journal of Philosophy 49 (3), 244-49.

Crombie, I. M. (1963) An Examination of Plato's Doctrines II. Plato on Knowledge and Reality. London.

Denyer, N. (2007) “The Phaedo's Final Argument." D. Scott, ed. Maieusis: Essays in Ancient Philosophy in Honour of Myles Burnyeat. Oxford, 87-96.

Dorter, K. (1982) Plato's Phaedo: An Interpretation. Toronto.

Duke, E. A., Hicken, W. F., Nicoll, W. S. M., Robinson, D. B. and Strachan, J. C. G., eds. (1995) Platonis Opera I: Euthiphro, Apologia, Crito, Phaedo, Cratylus, Theaetetus, Sophista, Politicus. Oxford.

Ebrey, D. (2013) "Making Room for Matter: Material Causes in the Phaedo and the Physics," Apeiron, 47 (2): 245-265.

Ferejohn, M. (2006) “Knowledge and the Forms in Plato," Benson, H. H., ed. A Companion to Plato. London, 146-61.

Fine, G. (1987) "Forms as Causes," Graeser, A., ed. Mathematik Und Metaphysik Bei Aristotle. Bern (reprinted and quoted from Fine, G. (2003) Plato on Knowledge and

${ }^{36}$ This paper benefited from insightful questions, remarks, and criticisms from audiences in São Paulo, Mexico City, and London. I am especially grateful to M. M. McCabe, Lesley Brown, Andrew Gregory, Fiona Leigh, David Sedley, Marco Zingano, Daniel R. N. Lopes, Liliana Carolina Sánchez Castro, Paulo Ferreira, Saloni de Souza, and Gabriela Martínez Sainz for their helpful comments and suggestions. 
Forms. Oxford, 69-112).

Fischer, F. (2002) "La «méthode» et Les «hypothèses» En «Phédon» 99d-102a," Revue Philosophique de Louvain 100 (4), 650-80.

Furley, D. (1989) Cosmic Problems: Essays on Greek and Roman Philosophy of Nature. Cambridge.

Gallop, D. (1975) Plato: Phaedo. New York.

Geddes, W. D., ed. (1863) The Phaedo of Plato. London.

Gould, T. (1963) Platonic Love. London.

Gregory, A. (2001) Plato's Philosophy of Science. London.

Gregory, A. (2016) Anaximander: A Re-Assessment. London \& New York.

Hankinson, R. J. J. (1998) Cause and Explanation in Ancient Greek Thought. Oxford.

Hermann, K. F. (1853) Platonis Dialogi Secundum Thrasylli Tetralogias Dispositi (6 Vols.). Leipzig.

Huby, P. M. (1959) "Phaedo 99d-102a," Phroensis 4 (1), 12-14.

Irwin, T. H. (1983) "Review of Doubt and Dogmatism: Studies in Hellenistic Epistemology by Malcolm Schofield; Myles Burnyeat; Jonathan Barnes (Editors)," Nous 17 (1), 126-34.

Kanayama, Y. (200o) "The Methodology of the Second Voyage and the Proof of the Souls Indestructibility in Plato's Phaedo," Oxford Studies in Ancient Philosophy XVIII, 41-100.

Kelsey, S. (2004) "Causation in the Phaedo," Pacific Philosophical Quarterly 85, 21-43.

Ledbetter, G. M. (1999) "Reasons and Causes in Plato: The Distinction between Ai $\tau i \alpha$ and A"i เov." Ancient Philosophy 19, 255-65.

Lennox, J. G. (1985) "Plato's Unnatural Teleology," O’Meara, D. J., ed. Platonic Investigations. Washington, 195-218.

Mason, A. (2013) “The Nous Doctrine in Plato's Thought," Apeiron 46 (3), 201-28.

McCabe, M. M. (1998) "Silencing the Sophists: The Drama of the Euthydemus," Proceedings of the Boston Area Colloquium in Ancient Philosophy 14, 137-76.

McCabe, M. M. (200o) Plato and his Predecessors. Cambridge.

Most, G. W., ed. (2006) Hesiod. Theogony. Works and Days. Testimonia. London.

Mueller, I. (1998) "Platonism and the Study of Nature," Gentzler, J. ed. Method in Ancient Philosophy. Oxford, 67-89.

Murphy, N. R. (1936) “The Deuteros Plous in the Phaedo," The Classical Quarterly 30 (2), 40-47.

Murphy, N. R. (1951) The Interpretation of Plato's Republic. Oxford.

Rocca, J., ed. (2017) Teleology in the Ancient World. Cambridge.

Ross, D. L. (1982) “The Deuteros Plous, Simmias' Speech, and Socrates' Answer to Cebes in Plato's Phaedo," Hermes 1 (110), 19-25.

Rowe, C. J., ed. (1993) Plato's Phaedo. Cambridge.

Schofield, M. (1997) “The Ionians." Taylor, C. C. W., ed. Routledge History of Philosophy: From the Begining to Plato. London.

Sedley, D. (1989) “Teleology and Myth," Proceedings of the Boston Area Colloquium in Ancient Philosophy 5 (1), 359-83.

Sedley, D. (1998) "Platonic Causes," Phronesis 43 (2), 114-32.

Sedley, D. (2007) Creationism and Its Critics in Antiquity. Berkeley \& Los Angeles. 
Sedley, D., and Long, A. (2011) Plato: Meno and Phaedo. Cambridge.

Sharma, R. (2009) 'Socrates' New Aitia: Causal and Metaphysical Explanations in Plato's Phaedo," Oxford Studies in Ancient Philosophy XXXVI, 137-77.

Shorey, P. (1888) "The Interpretation of the Timaeus," The American Journal of Philology 9 (4), 395-418.

Shorey, P. (1933) What Plato Said. Chicago.

Silverman, A. (1992) “Timaean Particulars," The Classical Quarterly, New Series 42 (1), 87113 .

Smyth, H. W. (1956) Greek Grammar. Edited and revised by Gordon M. Messing. Cambidge, MA.

Stallbaum, G., ed. (1850) Platonis Phaedo (Platonis Opera Omnia Vol I, Sec. II). 3rd (1850). Bern.

Stough, C. (1976) "Forms and Explanation in the Phaedo," Phronesis 21 (1), 1-30.

Taylor, C. C. W. (1969) "Forms as Causes in the Phaedo," Mind 78 (309), 45-59.

Verity, A., ed. (2007) Pindar. Complete Odes. Oxford.

Vlastos, G. (1969) "Reasons and Causes in the Phaedo," The Philosophical Review 78 (3), 291-325.

Wiggins, D. (1986) "Teleology and Good in Plato's Phaedo," Oxford Studies in Ancient Philosophy IV, 1-18.

Williamson, H., ed. (1904) The Phaedo of Plato. London.

Zeller, E. (1922) Die Philosophie Der Griechen in Ihrer Geschichtlichen Entwicklung, Vol. II, Part 1. $5^{\text {th }}$ ed. Leipzig. 